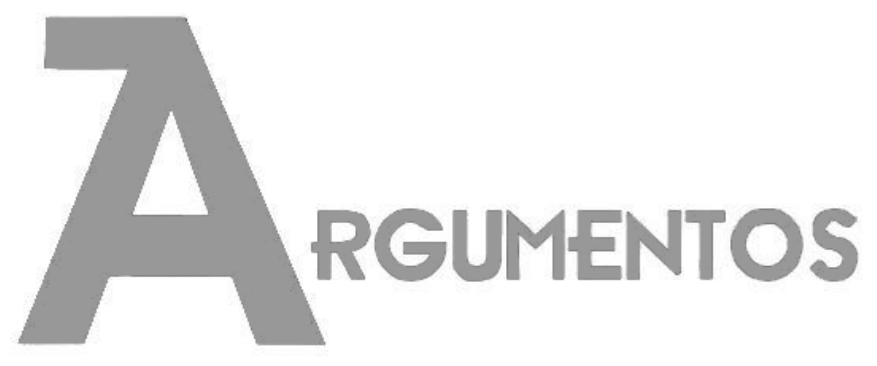

Vol. 17, n. 1, jan./jun. 2020 ISSN: 2527-2551 (online)

\title{
Organização e dinâmica da mobilização e participação política: os grêmios estudantis das escolas públicas e privadas de Santa Maria - RS
}

\author{
José Galdino Barreto Soares ${ }^{1}$ \\ José Carlos Martines Belieiro Junior ${ }^{2}$
}

Recebido em: 27/07/2019

Aprovado em: 31/10/2019

\begin{abstract}
Resumo: Este artigo analisa a organização e a dinâmica da mobilização política nos grêmios estudantis de Santa Maria - RS. O objetivo é verificar como atuam essas entidades e se conseguem mobilizar os estudantes não membros das direções a participarem das tomadas de decisão. Foram estudados sete grêmios, cinco da rede de ensino estadual e dois da particular, entre os anos de 2017 e 2018. Como procedimentos metodológicos, aplicou-se um questionário com os membros das direções e se analisou as atas dessas entidades. Em termos teóricos, leva-se em conta um dos resultados do estudo Albuquerque (1977), que indica que associações estudantis que realizam atividades do tipo culturais tendem ter baixa participação política. Os dados indicam que os grêmios estudantis analisados, caracterizam-se por serem organizações do tipo cultural com baixa capacidade de mobilização. Com isso, evidencia-se a hipótese que nas entidades estudantis desse tipo tendem a ser fraca a participação nas tomadas de decisões.
\end{abstract}

Palavras-chave: grêmios estudantis; participação; mobilização; engajamento Cívico; organizações estudantis.

\section{Organización y dinámica de la movilización y participación política: los fundamentos del estudiante de las escuelas públicas y privadas Santa Maria - RS}

\footnotetext{
${ }^{1}$ Graduado em Ciências Sociais pela Universidade Federal de Santa Maria - UFSM e mestre em Ciências Sociais pelo Programa de Pós-Graduação em Ciências Sociais PPGCS. Atualmente é Professor de Sociologia na rede de Ensino Estadual do Rio Grande do Sul. E-mail: galdino_barreto@yahoo.com.br. https://ORCID: 0000-0002-0529-8999

${ }^{2}$ Graduado em Ciências Sociais pela Universidade Estadual Paulista Júlio de Mesquita Filho - UNESP, Mestre em Ciência Política pela Universidade de São Paulo - USP e Doutor em Sociologia pela Universidade Federal do Paraná - UFPR. Atualmente é Professor Associado I no Departamento de Ciências Sociais da Universidade Federal de Santa Maria (UFSM), área de Ciência Política. E-mail: jcmbjunior@yahoo.com.br. ORCID: https://orcid.org/0000-0003-3507-6964.
} 
Artigo | Organização e dinâmica da mobilização e participação política: os grêmios estudantis das escolas públicas e privadas de Santa Maria - RS (SOARES, José Galdino Barreto; BELIEIRO JUNIOR, José Carlos Martines)

Resumen: Este artículo analiza la organización y la dinámica de la movilización política en los consejos estudiantiles de Santa María - RS. El objetivo es verificar cómo actúan estas entidades y si pueden movilizar a los estudiantes que no son miembros para participar en la toma de decisiones. Se estudiaron siete gremios, cinco del sistema escolar estatal y dos del privado, entre 2017 y 2018. Como procedimientos metodológicos, se aplicó un cuestionario con los miembros de las direcciones y se analizaron las actas de estas entidades. En términos teóricos, se considera uno de los resultados del estudio de Albuquerque (1977), que indica que las asociaciones de estudiantes que realizan actividades culturales tienden a tener una baja participación política. Los datos indican que los sindicatos estudiantiles analizados se caracterizan por ser organizaciones de tipo cultural con baja capacidad de movilización. Por lo tanto, se evidencia la hipótesis de que en los estudiantes las entidades de este tipo tienden a tener una participación débil en la toma de decisiones.

Palabras-clave: gremios de estudiantes; participación; movilización; compromiso cívico; organizaciones estudiantiles.

\title{
Organization and dynamics of mobilization and political participation: the students of the students of the public and private schools of Santa Maria - RS
}

\begin{abstract}
This article analyzes the organization and dynamics of political mobilization in the student councils of Santa Maria - RS. The objective is to verify how these entities act and if they are able to mobilize non-member students to participate in decision making. Seven guilds were studied, five from the state school system and two from private schools, between 2017 and 2018. As methodological procedures, a questionnaire was applied with the members of the directorates and the minutes of these entities were analyzed. In theoretical terms, one of the results of the Albuquerque study (1977) is considered, which indicates that student associations that perform cultural activities tend to have low political participation. The data indicate that the student unions analyzed are characterized by being cultural type organizations with low mobilization capacity. Thus, the hypothesis is evidenced that in student entities of this type tend to be weak participation in decision making.
\end{abstract}

Keywords: student groups; participation; Mobilization; civic engagement; etudent organizations.

\section{Introdução}

O caráter transitório dos estudantes pela escola faz com que o movimento estudantil secundarista tenha certa fluidez, essa renovação com saídas e entradas de novos alunos nos educandário colocam desafios aos grêmios estudantis em termos de continuidade. Ocorre, entretanto, que mesmo oscilando em termos quantitativos os grêmios estudantis em Santa Maria se mantêm com um número significativo de entidades em atividade. Atualmente, são sete escolas que contam com grêmios estudantis ativos que representam, segundo dados de 2017 publicados em 2018 pela $8^{a}$ Coordenadoria Regional de Educação, um total de 6.702 estudantes.

A participação dos discentes no movimento estudantil secundarista, além de se configurar como um relevante objeto de estudo para diversas áreas, sobretudo para as 
Artigo | Organização e dinâmica da mobilização e participação política: os grêmios estudantis das escolas públicas e privadas de Santa Maria - RS (SOARES, José Galdino Barreto; BELIEIRO JUNIOR, José Carlos Martines)

Ciências Sociais. Os grêmios estudantis nas escolas, como instâncias de representação dos estudantes secundaristas, têm como princípio representar democraticamente os estudantes tanto no ambiente interno da escola como também fora dela. Os grêmios estudantis respaldado pela Lei 7.398 de 4 de novembro 1985 e pela Lei № 8.069 de 13 de julho de 1990, a formação de um grêmio estudantil não pode ser impedida em uma escola pública ou particular. Em regra, essas duas leis dão aos estudantes o direito de organizarem diretorias compostas somente por alunos secundaristas e, assim, participarem de forma autônoma do grêmio estudantil na sua escola. De acordo com Verba, Schlozman e Brandy (2012) tão importantes quanto a "motivação" para participação política são as "redes sociais de apoio", pois essas tendem a funcionar como potenciais catalisadores da participação política. Essas redes sociais de apoio são tanto os grupos familiares ou de amigos, bem como outras redes sociais, essas localizadas em outros ambientes políticos, como por exemplo, nas escolas, nos locais de trabalho, nas associações voluntárias, ou nas instituições religiosas. Segundo Almond e Powell Jr. (1972), a estrutura escolar é uma influência poderosa na socialização política, pois expõe a criança e o jovem a papéis novos e especificamente políticos.

O objetivo principal deste estudo é verificar como atuam os grêmios estudantis de Santa Maria ${ }^{3}$, tentando apontar e explicar qual o tipo predominante de ação política realizada pelos seus dirigentes e se as atividades realizadas pelos grêmios estudantis estão sendo capazes de mobilizar a participação dos estudantes secundaristas. A questão que norteia esta pesquisa é a seguinte: as atividades políticas realizadas pelos dirigentes dos grêmios estudantis de Santa Maria estão mobilizando os outros estudantes a participarem da tomada de decisão?

Elegeu-se como objeto de estudo todos os grêmios estudantis em atividade nas escolas públicas estaduais e nas escolas privadas da cidade de Santa Maria, nos anos de 2017 e de 2018, por dois motivos: o primeiro, para poder delimitar com maior precisão o objeto de estudo, pois se trata do maior município em termos populacionais da região central do Estado Rio Grande do Sul, razão pela qual faz com que essa cidade concentre um número expressivo de estudantes secundaristas matriculados em escolas públicas e privadas. De acordo com os dados da Assessoria Pedagógica da 8a Coordenadoria

\footnotetext{
${ }^{3}$ Os grêmios estudantis analisados neste estudo estão nominados por letras do alfabeto, como, exemplo, $A, B, C, D E, F$ e G.
} 
Artigo | Organização e dinâmica da mobilização e participação política: os grêmios estudantis das escolas públicas e privadas de Santa Maria - RS (SOARES, José Galdino Barreto; BELIEIRO JUNIOR, José Carlos Martines)

Regional de Educação (8ª CRE) de Santa Maria - RS, no ano de 2017 foram matriculados 26.509,266 estudantes e em 2018 foram 29.991 discentes, distribuídos nos níveis do ensino fundamental municipal, estadual, federal e privado; e o segundo motivo se deu pelo fato de a cidade possuir movimento estudantil consolidado.

Em termos de procedimentos metodológicos, aplicou-se um questionário ${ }^{4}$ dividido em blocos, com perguntas fechadas e abertas aos estudantes dirigentes dos grêmios estudantis e analisou-se os documentos das atas dessas entidades, configurando, assim, uma amostra quantitativa e qualitativa não probabilística. Responderam o questionário 41 estudantes dirigentes de grêmios estudantis, desses alunos 13 são de escolas privadas e 28 de escolas públicas estaduais do município.

Este estudo trabalha com a seguinte hipótese: os grêmios estudantis de Santa Maria, em geral, se caracterizam como organizações que realizam atividades culturais, recreativas e assistenciais e tendem a ter uma baixa participação dos estudantes não membros da direção nas suas reuniões e assembleias. Nesse sentido, a hipótese deste estudo estabelece uma relação causal entre o tipo de organização e os tipos de atividades realizadas com a mobilização, ou seja, conforme o tipo de organização e atividade que realiza haverá uma maior ou menor participação. Há, portanto, uma relação de causa e efeito entre as atividades realizadas pelos grêmios estudantis e a intensidade da participação dos seus membros.

A hipótese desta pesquisa baseia-se em um dos resultados do estudo realizado por Albuquerque (1977) com estudantes latino-americanos ligados à política estudantil na Universidade de Louvain (Bélgica). Uma das conclusões da pesquisa realizada por esse autor é que a participação dos estudantes é mais intensa na "organização do tipo partidário", que são aquelas cujo objetivo é político, como, por exemplo, as atividades relacionadas à tomada do poder nas organizações estudantis. Em regra, esse tipo de organização tende a conter conteúdos ideológicos de ensino que também podem se relacionar com problemas gerais da sociedade. Desse modo, adaptou-se as categorias desenvolvidas por Albuquerque (1977) para se verificar se o resultado da pesquisa desse autor se confirma neste estudo dos grêmios estudantis de Santa Maria, em 2017 e 2018.

\footnotetext{
${ }^{4} \mathrm{O}$ estudo cumpriu com todos os dos aspectos éticos das pesquisas utilizando documentos básicos e fundamentais do protocolo e da pesquisa ética como: o anonimato, o termo de assentimento e livre consentimento esclarecido.
} 
Artigo | Organização e dinâmica da mobilização e participação política: os grêmios estudantis das escolas públicas e privadas de Santa Maria - RS (SOARES, José Galdino Barreto; BELIEIRO JUNIOR, José Carlos Martines)

A partir da hipótese, em termos teóricos, este trabalho opera com a concepção de que grêmios estudantis que realizam atividades culturais, recreativas e assistenciais tendem a não mobilizar os outros estudantes, os membros não dirigentes. Contexto esse que corrobora para que os processos decisórios sejam mais verticais e menos horizontais, ou seja, por falta de participação dos estudantes membros não dirigentes nas reuniões e assembleias, as tomadas de decisão nos grêmios estudantis de Santa Maria (gestão 2017 e 2018) tendem a se concentrar no grupo dirigente. A partir das análises dos livros Ata dos grêmios estudantis verificou-se que a maioria dos estudantes membros não dirigentes, tanto os da escola pública, quanto os da escola privada, restringem-se, apenas, à participação formal, ou seja, por meio dos processos eleitorais (votando na escolha da direção) e aos eventos realizados pelos grêmios estudantis.

Este artigo está organizado em três seções. Na primeira, faz-se uma breve revisão do debate teórico e classificatório acerca de estudos dos fenômenos da participação política, do engajamento cívico e da mobilização política, que são os três conceitos centrais deste estudo. Logo em seguida, na seção dois, apresentam-se os principais pressupostos teóricos adotados neste estudo. Nessa seção, também se delimita o campo teórico adaptando para este estudo alguns modelos e categorias elaboradas por Albuquerque (1977). Esse autor cria no capítulo IV do seu livro Movimento estudantil e consciência social na América Latina (1977), categorias e a partir delas analisa as atividades estudantis, classificando-as em três tipos de modalidades de acordo com os tipos de organização. Neste estudo, as categorias de Albuquerque são adaptadas e utilizadas como um tipo ideal e assim adotadas como instrumentos de análise, uma espécie de parâmetro para orientar a investigação quanto aos tipos de organizações e tipos de ações dos grêmios estudantis, bem como para mensurar a intensidade da participação nas atividades das organizações estudantis. Na terceira e última seção apresenta-se a descrição e análise dos dados empíricos que foram coletados neste estudo.

Introdução ao estudo da participação política: conceitos e modalidades

Há um consenso na bibliografia recente de que a participação política tem ocupado, ao longo do tempo, lugar de destaque na ciência política. Os primeiros 
Artigo | Organização e dinâmica da mobilização e participação política: os grêmios estudantis das escolas públicas e privadas de Santa Maria - RS (SOARES, José Galdino Barreto; BELIEIRO JUNIOR, José Carlos Martines)

trabalhos empíricos acerca da participação política concentraram-se no comportamento do voto, uma participação que se efetiva na politica institucional e nos meios tradicionais de ação, como a militância política e eleições. O principal propósito desta geração de estudos foi explicar porque alguns cidadãos optam em votar e participar dos processos eleitorais e outros não. De acordo com Ribeiro e Borba (2015), destacam-se nesse período os estudos de MILBRATH, 1965; VERBA e NIE, 1972; VERBA, SCHOLOZMAN e BRADY, 1995, entre outros. Nessa perspectiva, Milbrath (1981) define a participação política como aquelas ações pelas quais os cidadãos particulares buscam influenciar ou apoiar o governo e a política, um aprendizado social que predispõe os cidadãos a selecionarem e atuarem sobre os estímulos políticos que os induzem à participação e ao envolvimento. Segundo esse autor, a participação política é um ato singular exercido por comportamentos participativos num continuum ${ }^{5}$ a partir de custos e benefícios da qual se organiza as ações políticas das mais fáceis às mais difíceis.

Esta visão conceitual de que a participação política é algo vinculado ao ato de votar perdurou nas ciências sociais. Na medida em que surge um número maior de estudos empíricos, nasce a possibilidade de pesquisadores e estudiosos preparem algumas outras declarações acerca dos seus resultados em relação à participação política para além da participação convencional. O acúmulo de conhecimento possibilitou uma ampliação do conceito de participação e, ao mesmo tempo, uma melhor compreensão do ativismo político. Atualmente, a literatura acerca do tema participação política faz uma distinção clara entre a participação convencional (votar, participar de partido, sindicatos etc..) e a participação não convencional que se compõe a partir de repertórios alternativos como: protestos, boicotes, manifestações e etc..

Dentre os trabalhos clássicos acerca do estudo da participação política encontrase o livro Voice and Equality (1995) escrito pelos autores Sidney Verba, Kay Lehman Schlozman e Henry Brady. Nas pesquisas empíricas elaboradas por esses autores, estão algumas das bases mais sólidas do modelo de voluntarismo cívico, pois nelas encontram-

\footnotetext{
${ }^{5}$ Segundo Ribeiro e Borba ( 2015, p. 8-9) é : 1) expor-se a solicitações políticas; 2) votar; 3) participar de uma discussão política; 4) tentar convencer alguém a votar de determinado modo; 5) usar um distintivo político; 6) fazer contato com funcionários públicos; 7) contribuir com dinheiro a um partido ou candidato; 8) assistir a um comício ou assembleia; 9) dedicar-se a uma campanha política; 10) ser membro ativo de um partido político; 11) participar de reuniões onde se tomam decisões políticas; 12) solicitar contribuições em dinheiro para causas políticas; 13) candidatar-se a um cargo eletivo; 14) ocupar cargos públicos
} 
Artigo | Organização e dinâmica da mobilização e participação política: os grêmios estudantis das escolas públicas e privadas de Santa Maria - RS (SOARES, José Galdino Barreto; BELIEIRO JUNIOR, José Carlos Martines)

se algumas das condicionantes fundamentais da participação política e do ativismo político, como: engajamento, recursos e recrutamento. A base sobre a qual esse argumento se assenta diz respeito à voz política dos indivíduos, a qual é compreendida como qualquer atividade empreendida por indivíduos em organizações que almejam influenciar o governo em uma ação.

Nessa perspectiva, Sidney Verba, Kay Lehman Schlozman e Henry Brady (2012) compreendem que a participação política é amplamente moldada pelos cidadãos no envolvimento em instituições não oficiais da política, como por exemplo, no trabalho, nas igrejas e nas organizações voluntárias, pois essas dependem de certos recursos, especialmente de tempo, dinheiro e habilidades cívicas. Esses autores compreendem que para os indivíduos se tornem ativos na política é indispensável que eles queiram participar e para que isso aconteça é necessário certo nível de motivação, isto é, eles devem almejar participar, no entanto é preciso que os cidadãos se capacitem para serem ativos e isso só se dá participando. De acordo com Verba, Schlozman e Brandy (2012) tão importantes quanto a "motivação" para participação política são as "redes sociais de apoio". No entanto esses autores destacam que essas redes sociais de apoio assim como são capazes de fomentar a participação, podem também inibir a voz na atividade política, porque, muitas vezes, nelas são acentuadas as desigualdades na participação.

O foco analítico quais oferece uma importante contribuição para a compreensão de fatores que agem no fenômeno da participação política. Entretanto, neste estudo, não se considera apenas como instrumento participativo a participação convencional o voto e o envolvimento em campanhas eleitorais e sim outros repertórios de participação considerados não convencionais, a saber: participação em reuniões e assembleias, boicotes, passeatas, ações de protestos, bloqueio de tráfego.

O consenso em torno da participação política recai no entendimento de que há uma necessidade de que indivíduos queiram participar e de arenas políticas que mobilizem a participação. Diante disso, permanece imprescindível o diálogo desta literatura com as bases empíricas deste estudo, pois um dos objetivos desta pesquisa é identificar fatores que expliquem as dinâmicas da mobilização e da participação nos espaços de tomada de decisão dos grêmios estudantis das escolas públicas estaduais e particulares de Santa Maria. 
Artigo | Organização e dinâmica da mobilização e participação política: os grêmios estudantis das escolas públicas e privadas de Santa Maria - RS (SOARES, José Galdino Barreto; BELIEIRO JUNIOR, José Carlos Martines)

\section{A mobilização e o engajamento cívico dos jovens: as motivações e os desafios das organizações}

Os estudos das ações no interior das organizações dependem, antes de tudo, da definição teórica da organização. De acordo Van Deth (1997), as evidências empíricas coletadas por Almond e Verba (1963) realizada em cinco países demostram que os membros integrantes de associações têm níveis mais altos de consciência cívica, participação política e confiança social do que pessoas não envolvidas em associações. No entanto, segundo Metzger e Smetana (2010), o comportamento cívico ativo requer que os indivíduos se sintam motivados a se envolverem. De acordo com Kassimir e Flanagan (2010), os jovens não são meramente cidadãos em formação, mas agentes cívicos ativos no presente. Para esses autores, a cidadania é componente chave nesta transição de vida de adolescente para a vida adulta. O argumento é que os jovens, ao ocuparem papéis políticos ativos desenvolvem valores cívicos que aceleram a transição para a vida adulta.

A pesquisa de Cliff Zukin, Scott Keeter, Molly Andolina, Krista Jenkins e Michael X. Delli Carpini (2006) buscou compreender empiricamente o engajamento dos jovens em suas comunidades. Um dos resultados desse estudo é que os jovens estão participando ativamente em outras arenas cívicas e isso se deve, em grande parte, ao processo da substituição de geração. Nesse sentido, a participação política dos jovens envolve uma combinação contínua com o passado, porém misturada a uma variedade de novas perspectivas, como, por exemplo, a internet. O que os autores observam é o surgimento de novos padrões de engajamento público que possuem uma nova natureza política. Para sustentarem as suas análises, os autores desenvolvem um modelo que envolve oito passos que eles creem elevar a participação política e o engajamento cívico, que são as seguintes: "[...] socialização precoce; educação; evasão televisiva; identificação geracional; capital social; capital político; atitudes positivas em relação à política e ao governo; e mobilização" Zukin et al.(2006, p.124). Segundo esses autores, desses oito modelos, três aparecem como os mais potentes: as primeiras experiências de socialização, o capital político e a mobilização em particular. Por fim, esses autores 
Artigo | Organização e dinâmica da mobilização e participação política: os grêmios estudantis das escolas públicas e privadas de Santa Maria - RS (SOARES, José Galdino Barreto; BELIEIRO JUNIOR, José Carlos Martines)

concluem que os jovens estão prontos e dispostos a adicionar mais política em seu repertório de participação que está em evolução na esfera pública.

O estudo das ações no interior das organizações depende, antes de tudo, da definição teórica de mobilização. De acordo Jenkins (1981), a mobilização é o processo de agregar ou acumular recursos sob o controle coletivo de um grupo ou entidade corporativa para o propósito de se engajar em ação coletiva. Nesse sentido, Tilly (1978, p.7) escreve que "Mobilização é o processo pelo qual um grupo adquire controle coletivo sobre os recursos necessários para a ação". De acordo com McADAM, et al. (1996), a grande parte da literatura acerca da teoria da "Mobilização de Recursos" buscou saber como os movimentos sociais e outras formas de associativismo conseguiam, fora da política institucionalizada, agregar interesses à coletividade ao ponto dos indivíduos serem capazes de agir de modo organizado, criando estruturas de mobilização e redes de solidariedade. Nesse sentido, os movimentos sociais exercem dois importantes papéis: o primeiro como elementos dinâmicos no processo de aprendizado e formação da identidade social; e o segundo como projetos democráticos com potencial para iniciar os processos pelos quais a esfera pública pode ser revivida. (GOHN, 1997).

De acordo com McADAM et al. (1996), entende-se como estruturas de mobilização os veículos coletivos formais e informais que são disponíveis aos indivíduos para que estes se mobilizem, ou seja, tenham oportunidades políticas de participação e a partir desta se envolvam em ações coletivas. Segundo Jenkins (1981), existem três proposições centrais nas quais as análises de mobilização podem ser construídas: a primeira seria o nível de recursos que é mobilizado antes que os grupos possam se engajar em coletiva ação; a segunda é quando a mobilização de recursos da ação coletiva depende da existência de algum nível de organização, ou seja, se essa organização preexiste à ação coletiva é produzida por uma campanha de mobilização; e a terceira, por sua vez, tem na sua proposição central a tradução da mobilização em ação coletiva o que implica um cálculo complexo de custos e recompensas que repousa, principalmente, sobre os custos esperados de investir em ação coletiva, o esperado risco de repressão ou perda de recursos, e os ganhos previstos de ação.

Jenkins (1981), ressalta que quanto mais recursos possuir um grupo, mais provável é que ele se mobilize. Quanto à extensão da organização, o autor defende que 
Artigo | Organização e dinâmica da mobilização e participação política: os grêmios estudantis das escolas públicas e privadas de Santa Maria - RS (SOARES, José Galdino Barreto; BELIEIRO JUNIOR, José Carlos Martines)

esta também desempenha um papel central, especialmente na determinação do nível das lealdades do grupo e na probabilidade dos recursos que serão entregues, pois quanto mais organizado ou coeso for o grupo, menos recursos terão que ser gastos para comunicar ideias e assim iniciarem a ação coletiva.

Em relação ao coletivo e às lideranças, Gohn (2018) escreve que os coletivos organizados por jovens tendem a criar novas dinâmicas de ação, mais discursiva, com confronto de ideias e valores, podendo existir uma grande influência dos líderes. E sobre o papel político dos líderes na organização, a autora apresenta a denominação "organizações movimentalistas" que ela mesma criou e que constitui uma terminologia que caracteriza grupos de jovens que se aglutinam ao redor de alguns líderes ou formadores de opinião, os quais elaboram um plano de atividades e o executam sob a ótica de uma corporação. Percebe-se uma relação entre a organização, essa composta por bens materiais, regras e normas, e o comportamento dos indivíduos dirigentes que tendem a influenciar na mobilização e na participação dos outros indivíduos.

\section{A participação nas organizações estudantis: categorias e modelos de análises}

Grande parte das abordagens clássicas que apresentamos nesta segunda seção parte do pressuposto que as ações dos indivíduos nas organizações políticas são executadas em canais que os mobilizam e os encorajam a participação na organização. Uma das dificuldades que se enfrentou neste estudo foi localizar categorias que dessem conta de ordenar os dados empíricos de acordo com a hipótese teórica. Nesse sentido, fez-se necessário um debate teórico e metodológico para situar e classificar as atividades participativas nas organizações estudantis. Para isso, neste estudo se adota como referência o esquema de análise causal elaborado e apresentado por José Augusto Guilhon Albuquerque na sua tese de doutorado, defendida na Universidade Católica de Louvain, Bélgica (1972).

No estudo intitulado O Movimento Estudantil e Consciência Social na América Latina, Albuquerque (1977) realiza uma pesquisa empírica ${ }^{6}$ sobre o comportamento e as atitudes dos estudantes latino-americanos na política estudantil em Louvain, para

\footnotetext{
${ }^{6}$ Foram entrevistados 180 estudantes latinos americanos da universidade Católica de Louvain (Bélgica) entre os anos de 1965 e 1970.
} 
Artigo | Organização e dinâmica da mobilização e participação política: os grêmios estudantis das escolas públicas e privadas de Santa Maria - RS (SOARES, José Galdino Barreto; BELIEIRO JUNIOR, José Carlos Martines)

interpretar o movimento estudantil na América Latina. Na elaboração da sua tese, o autor cria, no capítulo IV, categorias e a partir delas analisa as atividades dos estudantes, classificando-as em modalidades de acordo com os tipos de organização.

De acordo com Albuquerque (1977), são três os tipos organizações estudantis: a organização do tipo partidário, a organização do tipo Sindical e a Organização cultural ou de serviços. A organização do tipo partidário é aquela cujo objetivo é político, como por exemplo, as atividades relacionadas à tomada do poder nas organizações estudantis. Em regra, esse tipo de organização tende a conter conteúdos ideológicos de ensino que também podem se relacionar com problemas gerais da sociedade. A organização do tipo sindical é referente à representação dos estudantes na universidade e aos problemas universitários do ponto de vista do funcionamento da instituição. Já a organização do tipo de serviços são as atividades e os diversos serviços econômicosociais prestados aos estudantes, bem como às suas reivindicações econômicas, como por exemplo, transporte público, bolsas de estudo, alojamento, etc.

A partir dos tipos de organização, Albuquerque (1977) classifica as atividades dos estudantes (os meios empregados) em outras três categorias que são as seguintes: Atividades Políticas ${ }^{7}$, Atividades de Formação ${ }^{8}$ e Atividades de Serviços $^{9}$. Nesse contexto, o que o autor busca saber é se os meios empregados estão estreitamente ligados ao tipo de organização. Ao examinar os conteúdos dos diferentes sistemas de atitudes com respeito à organização e ao movimento estudantil, o autor chega ao resultado que cada tipo de organização favorece a um modo particular de ação, tanto no interior quanto no exterior da Universidade.

De acordo com Albuquerque (1977), é o fato dos estudantes participarem, de maneira mais ou menos intensa, dessas diferentes práticas que permite que eles organizem as suas condutas de participação em função de certos valores e interpretarem a sua própria experiência no movimento estudantil. Em outras palavras,

\footnotetext{
${ }^{7}$ Atividade políticas que são atividades propriamente partidárias do tipo: a conquista da direção do diretório acadêmico ou mobilização dos estudantes em função de pautas politicas cujo conteúdo tenha relação, como por exemplo, com a política nacional.

${ }^{8}$ Atividades de formação sãos as que têm relação à organização de seminários, publicações ou ensino organizado pelos estudantes independente do conteúdo.

${ }^{9}$ Esta tem relação a categoria de serviços como cantinas, livrarias, restaurantes criados ou gerenciados pelos estudantes, incluindo serviços de emprego (bolsas), aconselhamento profissional, serviços prestados por representante de turma etc..
} 
Artigo | Organização e dinâmica da mobilização e participação política: os grêmios estudantis das escolas públicas e privadas de Santa Maria - RS (SOARES, José Galdino Barreto; BELIEIRO JUNIOR, José Carlos Martines)

o quadro situacional não determina as condutas dos estudantes, pois a ação das organizações estudantis é, em parte, determinada pelo sentido que os atores dão às organizações. Um dos resultados do estudo de Albuquerque é que as "atividades de formação" predominam nas "organizações culturais e de serviço", sendo que essas atividades de formação são mais numerosas nas organizações do tipo de serviços.

No que diz respeito à intensidade da participação nas atividades das organizações estudantis, essa participação vai depender do tipo de ação em que os membros estão engajados, o que também depende do engajamento formal dos membros na organização. Outro resultado da pesquisa do autor é que a participação dos estudantes é mais intensa nas organizações do tipo partidário e mais fraca nas organizações do tipo culturais e de serviços. Albuquerque $(1977$, p.89) escreve: "Parece de fato, que encontramos atitudes diferentes associadas a cada tipo de organização e que a participação é tanto mais intensa quando mais o ator é engajado formalmente."

Quanto à participação, Albuquerque (1977) a classifica em três tipos: a participação ideológica $^{10}$, a participação organizacional ${ }^{11}$ e a participação pessoal ou de consumo $^{12}$. Na organização do tipo Partidária acontecem atividades do tipo político, portanto será nesta que estudantes com participação ideológica tenderão a participar mais intensamente na tomada de decisão. Nas organizações do tipo Sindical, tende a acontecer atividades de formação e a participação mais intensa tende a ser a do tipo organizacional e nas organizações do tipo Cultural ou de Serviços as atividades tendem a ser de serviços e sendo a participação mais intensa a do tipo pessoal que é quando o estudante evoca sua responsabilidade pessoal e tende a criar ligações pessoais no seio da organização.

O presente estudo adota as três categorias elaboradas por Albuquerque (1977), a organização do tipo Partidária, a organização do tipo "Sindical" e a organização do tipo Cultural ou de Serviços como um tipo ideal para a análise dos dados coletados neste trabalho. Entretanto, dado o fato de que o estudo de Albuquerque foi desenvolvido nos anos de 1970 e este estudo do movimento estudantil secundarista dos grêmios estudantis de Santa Maria se deu, entre os anos de 2017 e 2018, fez-se necessário uma

\footnotetext{
${ }^{10}$ Corresponde a respostas que se referem a orientação do movimento.

${ }^{11}$ Corresponde à referência pessoal ou à representatividade da organização.

${ }^{12}$ Corresponde a respostas referentes à identificação pessoal dos estudantes, ou laços pessoais dentro da organização ou aos serviços prestados pela mesma.
} 
Artigo | Organização e dinâmica da mobilização e participação política: os grêmios estudantis das escolas públicas e privadas de Santa Maria - RS (SOARES, José Galdino Barreto; BELIEIRO JUNIOR, José Carlos Martines)

adaptação dessas categorias que foram renomeadas da seguinte forma: a organização do tipo Partidária passa a ser nominada organização secundarista do tipo l, a organização do tipo Sindical será a organização secundarista do tipo /l e a organização do tipo Cultural ou de Serviços será chamada de Organização secundarista do tipo III.

Desse modo, são consideradas como organização Secundarista do tipo / todas as organizações em que o grêmio estudantil realize atividades de cunho ideológico programático, cujas pautas ou reivindicações podem se relacionar com problemas gerais da sociedade que vão além do espaço da escola, como, por exemplo, atos, manifestos, protestos, aproximação política com outros grêmios estudantis e aproximação com entidades de representação estudantil, como, por exemplo, USE, UMES, UGES, UBES relação de trabalho com partidos políticos, relação de trabalho com sindicatos, relação de trabalho com movimentos sociais; relação de trabalho com líderes comunitários; entre outros.

Já a organização secundarista do tipo // são todas aquelas organizações cujo grêmio estudantil realize atividades do tipo organizacional, cujas pautas estejam relacionadas à estrutura e ao funcionamento da escola, como, por exemplo: encaminhar pedidos exigindo uma cantina na escola ou a mudança de horário do funcionamento da mesma; solicitar mudanças no horário de funcionamento da biblioteca e do acesso à quadra de esportes; pedidos formais de mudança de professor ou a destituição da direção; solicitar o uso ou o não uso de uniformes, bem como mudanças nos mesmos; requerer formalmente que se cumpram direitos de acessibilidades (rampas e elevadores para cadeirantes, banheiros adaptados etc.); solicitar internet; requerer armários; encaminhar pedidos de segurança dentro da escola, entre outros.

No que tange à categoria organização secundarista do tipo III são consideradas aquelas organizações cujas atividades realizadas pelo grêmio estudantil são culturais, recreativas e assistenciais, dentro ou fora da escola, como por exemplo: a organização de gincanas culturais; organização de feira de ciências, organização de excursões; organização de bailes; jogos interseríeis; campanhas de arrecadação de agasalhos; campanha de doação de sangue; visitas ou apadrinhamento de moradores em asilos; visitas ou apadrinhamento de abrigos ou lares de crianças que esperam por adoção, entre outros. 
Artigo | Organização e dinâmica da mobilização e participação política: os grêmios estudantis das escolas públicas e privadas de Santa Maria - RS (SOARES, José Galdino Barreto; BELIEIRO JUNIOR, José Carlos Martines)

A partir destes três tipos ideais de organizações, a organização secundarista do tipo I, a organização secundarista do tipo II e a organização secundarista do tipo III, verifica-se como se caracteriza as organizações estudantis em Santa Maria, bem como as regularidades quanto à capacidade das atividades realizadas pelas organizações em mobilizar a participação dos estudantes secundaristas nos grêmios estudantis de Santa Maria.

\section{Discussão e análises dos dados}

Com base nos dados coletados e no arcabouço teórico deste estudo, procurouse analisar os dados obtidos por meio do questionário e das atas dos grêmios estudantis. Os dados analisados revelam que é possível verificar traços gerais do perfil dominante dos alunos que compõem as direções dos grêmios estudantis. Em geral, estas direções são compostas, na sua maioria, por estudantes do sexo feminino. São alunos que estão na faixa etária dos 16 a 17 anos e cursam o 2 e 3ำ anos do ensino médio diurno (manhã), como demonstram as quatro tabelas abaixo do 1 a 4 :

\begin{tabular}{ccc|c|c|c} 
& \multicolumn{5}{c}{ Gênero } \\
& Frequência & Porcentagem & $\begin{array}{c}\text { Porcentagem } \\
\text { válida }\end{array}$ & $\begin{array}{c}\text { Porcentagem } \\
\text { acumulativa }\end{array}$ \\
\hline \multirow{2}{*}{$\begin{array}{c}\text { Válid } \\
0\end{array}$} & $\begin{array}{c}\text { Masculin } \\
0\end{array}$ & 10 & 24,4 & 24,4 & 24,4 \\
\cline { 2 - 6 } & Feminino & 31 & 75,6 & 75,6 & 100,0 \\
\cline { 2 - 6 } & Total & 41 & 100,0 & 100,0 & \\
\hline
\end{tabular}

Tabela 1: Fonte próprio autor

Data de nascimento

\begin{tabular}{ccc|c|c|c} 
& Frequência & Porcentagem & $\begin{array}{c}\text { Porcentagem } \\
\text { válida }\end{array}$ & $\begin{array}{c}\text { Porcentagem } \\
\text { acumulativa }\end{array}$ \\
\hline & $\begin{array}{c}199 \\
4\end{array}$ & 1 & 2,4 & 2,4 & 2,4 \\
\hline $\begin{array}{c}199 \\
6\end{array}$ & 1 & 2,4 & 2,4 & 4,9 \\
\hline $\begin{array}{c}199 \\
\text { Válid }\end{array}$ & $\begin{array}{c}19 \\
89\end{array}$ & 1 & 2,4 & 2,4 & 7,3 \\
\hline $\begin{array}{c}199 \\
9\end{array}$ & 2 & 4,9 & 4,9 & 12,2 \\
\hline $\begin{array}{c}200 \\
0\end{array}$ & 6 & 14,6 & 14,6 & 26,8 \\
\hline
\end{tabular}


Artigo | Organização e dinâmica da mobilização e participação política: os grêmios estudantis das escolas públicas e privadas de Santa Maria - RS (SOARES, José Galdino Barreto; BELIEIRO JUNIOR, José Carlos Martines)

\begin{tabular}{cc|c|c|c}
\hline $\begin{array}{c}200 \\
2\end{array}$ & 8 & 19,5 & 19,5 & 85,4 \\
\hline $\begin{array}{c}200 \\
3\end{array}$ & 6 & 14,6 & 14,6 & 100,0 \\
\hline $\begin{array}{c}\text { Tota } \\
1\end{array}$ & 41 & 100,0 & 100,0 & \\
\hline
\end{tabular}

Tabela 2: Fonte próprio autor

Série

\begin{tabular}{|c|c|c|c|c|c|}
\hline & & Frequência & Porcentagem & $\begin{array}{l}\text { Porcentagem } \\
\text { válida }\end{array}$ & $\begin{array}{c}\text { Porcentagem } \\
\text { acumulativa }\end{array}$ \\
\hline \multirow{6}{*}{$\begin{array}{c}\text { Válid } \\
\text { o }\end{array}$} & $\begin{array}{c}80 \\
\text { ano }\end{array}$ & 2 & 4,9 & 4,9 & 4,9 \\
\hline & $\begin{array}{c}90 \\
\text { ano }\end{array}$ & 7 & 17,1 & 17,1 & 22,0 \\
\hline & $\begin{array}{c}10 \\
\text { ano }\end{array}$ & 6 & 14,6 & 14,6 & 36,6 \\
\hline & $\begin{array}{c}20 \\
\text { ano }\end{array}$ & 12 & 29,3 & 29,3 & 65,9 \\
\hline & $\begin{array}{c}\text { 3o } \\
\text { ano }\end{array}$ & 14 & 34,1 & 34,1 & 100,0 \\
\hline & Total & 41 & 100,0 & 100,0 & \\
\hline
\end{tabular}

Tabela 3: Fonte próprio autor

\begin{tabular}{ccc|c|c|c} 
& \multicolumn{6}{c}{ Estuda em qual turno? } \\
& & Frequência & Porcentagem & $\begin{array}{c}\text { Porcentagem } \\
\text { válida }\end{array}$ & $\begin{array}{c}\text { Porcentagem } \\
\text { acumulativa }\end{array}$ \\
\hline \multirow{2}{*}{\begin{tabular}{c} 
Manh \\
\multirow{2}{*}{$\begin{array}{c}\text { ã } \\
0\end{array}$}
\end{tabular}} & 28 & 68,3 & 68,3 & 68,3 \\
\cline { 2 - 6 } & Tarde & 8 & 19,5 & 19,5 & 87,8 \\
\cline { 2 - 6 } & Noite & 5 & 12,2 & 12,2 & 100,0 \\
\hline & Total & 41 & 100,0 & 100,0 & \\
\hline
\end{tabular}

Tabela 4: Fonte próprio autor

Os dados analisados revelam que é possível verificar traços gerais do perfil dominante dos alunos que compõem as direções dos grêmios estudantis. Em geral, estas direções são compostas, na sua maioria, por estudantes do sexo feminino. São alunos (as) que estão na faixa etária dos 16 a 17 anos e cursam o 2ํ e 3 anos do ensino médio diurno (manhã), como demonstram as quatro tabelas acima do 1 a 4 .

Ainda sobre o perfil dos estudantes dirigentes, as amostras revelam que a maioria dos alunos (as) que compõe as direções dos grêmios estudantis estão participando pela primeira vez. Os dados mostram que os estudantes dirigentes tendem a participar através do voto nas eleições das escolas públicas que são as que elegem a direção escolar pelo voto, visto que as duas escolas particulares não realizam eleições. 
Artigo | Organização e dinâmica da mobilização e participação política: os grêmios estudantis das escolas públicas e privadas de Santa Maria - RS (SOARES, José Galdino Barreto; BELIEIRO JUNIOR, José Carlos Martines)

Os dados revelaram que a maiorias dos estudantes dirigentes que possuem idade para obterem o título de eleitor possuem esse documento eleitoral, no entanto só a metade dos que possuem esse documento votaram em eleições. Outro dado revelado pelo questionário é que a maioria dos dirigentes dos grêmios estudantis não possuem filiação partidária, dos 41 alunos entrevistados, somente 5 alunos estão filados a partidos políticos. Sobre o interesse em participar da direção do grêmio estudantil, são muitas as razões, no entanto percebe-se que, de um modo geral, o interesse em participar da direção do grêmio estudantil se dá pelo desejo e a oportunidade de colaborar com a escola. Para esses dirigentes o seu maior desafio ou dificuldade foi mobilizar a participação dos outros colegas que não fazem parte da direção do grêmio estudantil.

Quanto a estrutura socioeconômica das famílias dos estudantes dirigentes dos grêmios estudantis de Santa Maria os dados mostraram uma diferença entre os alunos das escolas públicas e os das escolas privadas. Nas questões que se referem à escolaridade dos pais, verifica-se que, em geral, os pais e as mães dos dirigentes possuem o ensino médio completo, os que possuem o Ensino Superior completo são, na sua grande maioria, pais e as mães dos dirigentes dos grêmios das escolas particulares, fato relatado anteriormente na sessão da descrição dos dados de pesquisa.

A respeito das profissões desses pais, essas tendem a ter relação com o grau de escolaridade, ou seja, conforme o grau de escolaridade é a atividade profissional dos pais. Os dirigentes dos grêmios estudantis das escolas particulares são os que têm os pais com as profissões mais prestigiadas em termos financeiros, por exemplo, médicos, advogados, engenheiros, etc.. Já as atividades profissionais dos pais que possuem uma baixa escolaridade, como por exemplo, o ensino fundamental incompleto, são: auxiliar de serviços gerais, autônomos, diaristas, domésticas e um percentual de mães dedicadas às atividades do lar. Houve um número de dirigentes, principalmente aqueles que estudam na escola pública Estadual, que escreveram que não têm pai. Sobre a filiação partidária dos pais dos dirigentes, em geral são poucos os que possuem vínculos com partidos políticos, apenas três pais e quatro mães, como demostram as tabelas de 5 a 8. 
Artigo | Organização e dinâmica da mobilização e participação política: os grêmios estudantis das escolas públicas e privadas de Santa Maria - RS (SOARES, José Galdino Barreto; BELIEIRO JUNIOR, José Carlos Martines)

\begin{tabular}{|c|c|c|c|c|c|}
\hline \multicolumn{6}{|c|}{ Escolaridade Pai } \\
\hline & & Frequência & $\begin{array}{c}\text { Porcentage } \\
\text { m }\end{array}$ & $\begin{array}{l}\text { Porcentagem } \\
\text { válida }\end{array}$ & $\begin{array}{c}\text { Porcentage } \\
\mathrm{m} \\
\text { acumulativa }\end{array}$ \\
\hline \multirow{8}{*}{ Válido } & $\begin{array}{l}\text { Ensino Fundamental } \\
\text { Incompleto }\end{array}$ & 2 & 4,9 & 5,4 & 5,4 \\
\hline & $\begin{array}{c}\text { Ensino Fundamental } \\
\text { Completo }\end{array}$ & 3 & 7,3 & 8,1 & 13,5 \\
\hline & Ensino Médio Completo & 17 & 41,5 & 45,9 & 59,5 \\
\hline & Ensino Superior Incompleto & 1 & 2,4 & 2,7 & 62,2 \\
\hline & Ensino Superior Completo & 10 & 24,4 & 27,0 & 89,2 \\
\hline & Superior com Pós & 3 & 7,3 & 8,1 & 97,3 \\
\hline & Não sei & 1 & 2,4 & 2,7 & 100,0 \\
\hline & Total & 37 & 90,2 & 100,0 & \\
\hline $\begin{array}{c}\text { Omiss } \\
0\end{array}$ & Sistema & 4 & 9,8 & & \\
\hline & Total & 41 & 100,0 & & \\
\hline
\end{tabular}

Tabela 5: Fonte próprio autor

\section{Escolaridade Mãe}

\begin{tabular}{|c|c|c|c|c|c|}
\hline \\
\hline & & Frequência & Porcentagem & $\begin{array}{l}\text { Porcentagem } \\
\text { válida }\end{array}$ & $\begin{array}{c}\text { Porcentage } \\
\mathrm{m} \\
\text { acumulativa }\end{array}$ \\
\hline \multirow{8}{*}{$\begin{array}{c}\text { Válid } \\
\text { o }\end{array}$} & $\begin{array}{l}\text { Ensino Fundamenta } \\
\text { Incompleto }\end{array}$ & 3 & 7,3 & 7,3 & 7,3 \\
\hline & $\begin{array}{l}\text { Ensino Fundamental } \\
\text { Completo }\end{array}$ & 3 & 7,3 & 7,3 & 14,6 \\
\hline & Ensino Médio Incompleto & 3 & 7,3 & 7,3 & 22,0 \\
\hline & Ensino Médio Completo & 17 & 41,5 & 41,5 & 63,4 \\
\hline & Ensino Superior Completo & 12 & 29,3 & 29,3 & 92,7 \\
\hline & Superior com Pós & 2 & 4,9 & 4,9 & 97,6 \\
\hline & Não sei & 1 & 2,4 & 2,4 & 100,0 \\
\hline & Total & 41 & 100,0 & 100,0 & \\
\hline
\end{tabular}

Tabela 6: Fonte próprio autor 
Artigo | Organização e dinâmica da mobilização e participação política: os grêmios estudantis das escolas públicas e privadas de Santa Maria - RS (SOARES, José Galdino Barreto; BELIEIRO JUNIOR, José Carlos Martines)

Seu pai tem filiação partidária?

\begin{tabular}{ccc|c|c|c} 
& & Frequência & Porcentagem & $\begin{array}{c}\text { Porcentagem } \\
\text { válida }\end{array}$ & Porcentagem acumulativa \\
\hline \multirow{3}{*}{ Válido } & Sim & 3 & 7,3 & 7,9 & 7,9 \\
\cline { 2 - 6 } & Não & 35 & 85,4 & 92,1 & 100,0 \\
\cline { 2 - 6 } & Total & 38 & 92,7 & 100,0 & \\
\hline \multirow{2}{*}{ Omisso } & Sistema & 3 & 7,3 & & \\
\hline \multicolumn{2}{c}{ Total } & 41 & 100,0 & & \\
\hline
\end{tabular}

Tabela 7: Fonte próprio autor

Sua mãe tem filiação partidária?

\begin{tabular}{|c|c|c|c|c|c|}
\hline & & Frequência & Porcentagem & $\begin{array}{c}\text { Porcentagem } \\
\text { válida }\end{array}$ & Porcentagem acumulativa \\
\hline \multirow{3}{*}{$\begin{array}{c}\text { Válid } \\
\text { o }\end{array}$} & $\operatorname{Sim}$ & 4 & 9,8 & 9,8 & 9,8 \\
\hline & Não & 37 & 90,2 & 90,2 & 100,0 \\
\hline & $\begin{array}{c}\text { Tota } \\
\text { । }\end{array}$ & 41 & 100,0 & 100,0 & \\
\hline
\end{tabular}

Tabela 8: Fonte próprio autor

Verificou-se, a partir das respostas à questão que se relacionava à inserção dos estudantes dirigentes no mundo do trabalho que, em geral, os dirigentes dos grêmios estudantis estudam e não possuem compromissos laborais. A parcela de $22 \%$ dos dirigentes que possuem compromissos trabalhistas é composta por estudantes de escolas públicas, cujos pais possuem empregos de baixa remuneração, escolaridade baixa e incompleta (ver tabela 9).

Você trabalha?

\begin{tabular}{ccc|c|c|c} 
& & Frequência & Porcentagem & $\begin{array}{c}\text { Porcentagem } \\
\text { válida }\end{array}$ & $\begin{array}{c}\text { Porcentagem } \\
\text { acumulativa }\end{array}$ \\
\hline \multirow{2}{*}{$\begin{array}{c}\text { Válid } \\
0\end{array}$} & Sim & 9 & 22,0 & 22,0 & 22,0 \\
\cline { 2 - 6 } & \begin{tabular}{c} 
Não \\
\cline { 2 - 6 }
\end{tabular} & 32 & 78,0 & 78,0 & 100,0 \\
\hline
\end{tabular}

Tabela 9: Fonte próprio autor

Sobre a relação das direções dos grêmios estudantis com as direções das escolas, os dados indicam que de um modo geral é boa. Desse modo, para a maioria dos dirigentes dos grêmios estudantis as direções escolares são aliadas importantes. A 
Artigo | Organização e dinâmica da mobilização e participação política: os grêmios estudantis das escolas públicas e privadas de Santa Maria - RS (SOARES, José Galdino Barreto; BELIEIRO JUNIOR, José Carlos Martines)

maioria das escolas disponibiliza (nomeia) um professor conselheiro que é quem faz a interlocução com os grêmios estudantis nas escolas. Apenas os dirigentes do grêmio estudantil " $D$ " escreveram que possuem uma relação complicada com a direção, falta de incentivo e abertura como demostra os seguintes relatos: “É complicado, não temos abertura", "Dialogável, entretanto por vezes não compreendida por parte da direção da escola".

De um modo geral os grêmios estudantis possuem uma estrutura boa, o que segundo Jenkins (1981) pode estar ligado às condições ideais para a mobilização, pois a estrutura, como por exemplo, a mão de obra, sala de reunião, entre outros são meios necessários para a subsistência e a legitimidade social do grupo. Em geral, para esse autor, quanto mais recursos (estrutura) possuir um grupo, mais provável é que ele mobilize novos membros. Nesse sentido, os dados demostram que apenas dois dos sete grêmios estudantis não têm um lugar próprio reservado para o seu uso exclusivo na escola, assim como os documentos do estatuto e a da ata como demostram as tabelas de 10 a 12.

O Grêmio dispõe de um espaço próprio na escola como, por exemplo, uma sala?

\begin{tabular}{ccc|c|c|c} 
& & Frequência & Porcentagem & $\begin{array}{c}\text { Porcentagem } \\
\text { válida }\end{array}$ & $\begin{array}{c}\text { Porcentagem } \\
\text { acumulativa }\end{array}$ \\
\hline \multirow{2}{*}{$\begin{array}{c}\text { Válid } \\
0\end{array}$} & Sim & 29 & 70,7 & 70,7 & 70,7 \\
\cline { 2 - 6 } & \begin{tabular}{c} 
Não \\
\cline { 2 - 6 }
\end{tabular} & 12 & 29,3 & 29,3 & 100,0 \\
\hline
\end{tabular}

Tabela 10: Fonte próprio autor

\begin{tabular}{ccc|c|c|c} 
& \multicolumn{6}{c}{ O Grêmio possui o Documento do Estatuto? } \\
& & Frequência & Porcentagem & $\begin{array}{c}\text { Porcentagem } \\
\text { válida }\end{array}$ & $\begin{array}{c}\text { Porcentagem } \\
\text { acumulativa }\end{array}$ \\
\hline \multirow{2}{*}{$\begin{array}{c}\text { Válid } \\
\text { o }\end{array}$} & Sim & 33 & 80,5 & 80,5 & 80,5 \\
\cline { 2 - 6 } & Não & 8 & 19,5 & 19,5 & 100,0 \\
\cline { 2 - 6 } & $\begin{array}{c}\text { Tota } \\
\text { I }\end{array}$ & 41 & 100,0 & 100,0 & \\
\hline
\end{tabular}

Tabela 11: Fonte próprio autor 
Artigo | Organização e dinâmica da mobilização e participação política: os grêmios estudantis das escolas públicas e privadas de Santa Maria - RS (SOARES, José Galdino Barreto; BELIEIRO JUNIOR, José Carlos Martines)

\begin{tabular}{ccc|c|c|c}
\multicolumn{7}{c}{ O Grêmio possui o documento de Ata? } & Porcentagem \\
& & Frequência & Porcentagem & $\begin{array}{c}\text { Porcentagem } \\
\text { válida }\end{array}$ & $\begin{array}{c}\text { Porcumulativa } \\
\text { acumy }\end{array}$ \\
\hline \multirow{2}{*}{$\begin{array}{c}\text { Válid } \\
0\end{array}$} & Sim & 28 & 68,3 & 68,3 & 68,3 \\
\cline { 2 - 6 } & Não & 13 & 31,7 & 31,7 & 100,0 \\
\cline { 2 - 6 } & Total & 41 & 100,0 & 100,0 & \\
\hline
\end{tabular}

Tabela 12: Fonte próprio autor

As respostas de um dos grupos dirigentes do grêmio estudantil indicaram que esse não possui o livro ata. E quando questionados de que maneira são registradas e arquivadas as atividades do grêmio estudantil, os estudantes escreveram que os registros das atividades são feitos através de publicações na página do grêmio estudantil no facebook.

Quanto aos tipos de atividades realizadas pelos grêmios estudantis essas, em média, caracterizam-se por serem do tipo cultural, recreativo e assistencial, como, por exemplo, a organização de gincanas, organização de feira de ciências, jogos interséris, campanhas de arrecadação de agasalhos, campanha de doação de sangue; festas de natal, entre outros.

Analisados alguns livros atas dos grêmios estudantis verificou-se que na maioria dos grêmios estudantis, são registradas somente as reuniões e as assembleias que foram realizadas pela entidade. Outro dado revelado a partir das análises das atas dos grêmios estudantis é o número baixo de assinaturas de presença dos alunos nas reuniões e nas assembleias. De um modo geral, só estão registradas no livro ata as assinaturas dos estudantes dirigentes, portanto é possível se delinear que as reuniões e as assembleias dos grêmios estudantis, de um modo geral, são realizadas com a presença de um número baixo de estudantes, com exceção das eleições para escolha da direção do grêmio estudantil.

$\mathrm{Na}$ questão relativa às dificuldades encontradas pelos estudantes dirigentes durante a gestão do grêmio estudantil, as repostas foram bastante diversas, desde "nenhuma dificuldade" até "dificuldade em dar um aviso em sala de aula". Considerando todas as respostas dadas pelos discentes, a que apareceu com maior frequência, foi a ligada ao fato de "não conseguir fazer com que os outros colegas de escola, os não membros da direção participem das atividades do grêmio estudantil". 
Artigo | Organização e dinâmica da mobilização e participação política: os grêmios estudantis das escolas públicas e privadas de Santa Maria - RS (SOARES, José Galdino Barreto; BELIEIRO JUNIOR, José Carlos Martines)

As amostras levantadas no questionário quando confrontadas com os registros do livro ata, revelaram que, em geral, as reuniões nos grêmios estudantis são realizadas duas vezes por semestre, enquanto as assembleias são realizadas uma vez por ano. Quanto às tomadas de decisões nos grêmios estudantis, ao confrontarmos as respostas dos estudantes no questionário com o que está registrado no livro ata, verificou-se que, em média, as decisões nos grêmios estudantis são tomadas apenas pelos grupos dirigentes. Já sobre a participação dos estudantes não membros da direção na tomada de decisão no grêmio estudantil, a resposta mais frequente foi que a participação de muitos alunos ajuda na tomada de decisão, e um grupo pequeno de dirigentes respondeu que essa participação atrapalha a tomada de decisão da direção.

$\mathrm{Na}$ questão que buscou saber como os dirigentes percebem a participação dos outros estudantes não membros da direção, as respostas que apareceram com maior frequência foram de "média" a "baixa" como mostra a tabela 13.

\section{Como você considera a participação dos alunos da sua escola no Grêmio Estudantil?}

\begin{tabular}{ccc|c|c|c} 
& Frequência & Porcentagem & $\begin{array}{c}\text { Porcentagem } \\
\text { válida }\end{array}$ & $\begin{array}{c}\text { Porcentagem } \\
\text { acumulativa }\end{array}$ \\
\hline \multirow{2}{*}{ Baixa } & 14 & 34,1 & 34,1 & 34,1 \\
\cline { 2 - 5 } & $\begin{array}{c}\text { Médi } \\
\text { a }\end{array}$ & 25 & 61,0 & 61,0 & 95,1 \\
\cline { 2 - 5 } & Alta & 2 & 4,9 & 4,9 & 100,0 \\
\hline & 41 & 100,0 & 100,0 & \\
\hline
\end{tabular}

Tabela 13: Fonte próprio autor

Quando a pergunta foi sobre como é a relação do grêmio estudantil com as outras entidades de representação, como a USE, UMES e UBES, de maneira geral, as respostas dos dirigentes dos grêmios estudantis de Santa Maria foram de não terem nenhum contato com essas entidades. Já sobre a capacidade da direção dos grêmios estudantis em mobilizar a participação dos outros estudantes não dirigentes, a resposta que apareceu com maior frequência foi a de não estarem conseguindo mobilizar.

Nas bases teóricas deste estudo está uma breve discussão sobre a participação política e estudos das ações no interior das organizações. As evidências empíricas 
Artigo | Organização e dinâmica da mobilização e participação política: os grêmios estudantis das escolas públicas e privadas de Santa Maria - RS (SOARES, José Galdino Barreto; BELIEIRO JUNIOR, José Carlos Martines)

coletadas por parte de alguns autores que compõem o arcabouço teórico deste estudo, como por exemplo, Albuquerque (1977) sustenta que a participação política tende a ter relação com o tipo de atividade realizada pela organização, ou seja, determinados tipos de atividades promovidas pela organização tendem a gerar maior ou menor participação. Parte da fundamentação teórica deste estudo reside em três modelos, em três tipos ideiais que foram adaptados da pesquisa de Albuquerque (1977): a "organização Secundarista do tipo I", a "organização secundarista do tipo II" e a "organização secundarista do tipo III".

Com base nessas categorias, procurou-se, neste estudo, compreender as amostras extraídas no campo de pesquisa no que tange a capacidade de mobilização dos grêmios estudantis e à participação dos estudantes. A partir de uma análise geral dos dados é possível se delinear que os grêmios estudantis de Santa Maria na gestão de 2017 e 2018 se caracterizam por serem "organização secundarista do tipo III", que são aquelas organizações cujos tipos de atividades realizadas pelas direções são do tipo cultural, recreativa e assistencial. Fato que pode ser um dos motivos para que, de modo geral, esses grêmios estudantis não consigam mobilizar a participação dos estudantes não membros da direção, pois os dados revelaram que a participação dos alunos nos grêmios estudantis se caracteriza por ser baixa. Nesse sentido, a hipótese testada de que os grêmios estudantis de Santa Maria, na sua maioria, tendem a se caracterizar como organizações secundaristas do tipo III, por realizarem atividades culturais, recreativas e assistenciais, sendo essa uma das razões da baixa participação dos estudantes não membros da direção nas tomadas de decisões é confirmada.

\section{Considerações finais}

Um dos principais objetivos deste estudo foi verificar quais os grêmios estavam realizando e, a partir da verificação dessas ações, identificar em qual modelo de organização essas direções se enquadrariam, bem como verificar se estas organizações estavam conseguindo ou não mobilizar os estudantes não dirigentes a participarem das reuniões e assembleias onde são discutidas as pautas e são tomadas as decisões dos grêmios estudantis. Ao longo deste trabalho, se utilizou as letras $A, B, C, D, E, F, G$ para 
Artigo | Organização e dinâmica da mobilização e participação política: os grêmios estudantis das escolas públicas e privadas de Santa Maria - RS (SOARES, José Galdino Barreto; BELIEIRO JUNIOR, José Carlos Martines)

nominar os setes grêmios estudantis em virtude do compromisso assumido de manter em sigilo sobre a identidade das agremiações.

Sobre o perfil dos estudantes dirigentes os dados coletados revelaram que, de modo geral, as direções de grêmios estudantis de Santa Maria são compostas por discentes, em sua maioria, do sexo feminino, pertencentes à faixa etária dos 16 a 17 anos, cursando o 2 e e 30 anos do ensino médio diurno, sem ocupação laboral e sem filiação partidária. Sobre o perfil dos pais desses dirigentes, percebeu-se uma diferença na escolaridade e nas atividades profissionais desempenhadas por eles. Os pais dos dirigentes dos grêmios estudantis das escolas particulares são aqueles que possuem maior escolaridade e os que possuem as atividades profissionais mais rentáveis.

Sobre a estrutura dos sete grêmios estudantis pesquisados, cinco grupos de dirigentes indicaram que possuem um local próprio onde são discutidos os assuntos de interesse da entidade. Em relação ao estatuto e ao livro ata, dois dos sete grêmios escreveram que não possuem o livro ata, um da escola pública e um da escola particular.

Outro aspecto revelado neste estudo diz respeito à atuação dos grêmios estudantis que, comumente, não se relacionam entre si e tampouco com as outras entidades de representação estudantil, como a USE, a UMES, a UGES e a UBES. Três possibilidades podem explicar a razão desse insulamento dos grêmios estudantis de Santa Maria: a primeira seria pelo distanciamento das entidades secundaristas de representação nas suas três esferas, municipal (USE e UMES), estadual (UGES) e federal (UBES) que não possuem um projeto com foco na aproximação dos grêmios estudantis da cidade de Santa Maria; a segunda pode estar na resistência por parte das direções das escolas públicas e particulares que não autorizam a outras entidades adentrarem no espaço da escola; a terceira possiblidade seria pela carga de estudos dos alunos e pelas greves e paralizações que fazem com que os discentes foquem mais na aprendizagem em sala de aula do que nas atividades dos grêmios estudantis.

Com base em alguns dados coletados durante a pesquisa, constatou-se que, historicamente, a ininterrupção é um desafio a ser enfrentado pelos grêmios estudantis nas escolas de Santa Maria. O caráter transitório dos estudantes pela escola faz com que o os grêmios estudantis enfrentem o desafio da renovação das direções.

Revelou-se neste estudo que as atividades dos grêmios estudantis são dos tipos culturais, recreativas e assistenciais, ou seja, dos sete grêmios estudantis seis se 
Artigo | Organização e dinâmica da mobilização e participação política: os grêmios estudantis das escolas públicas e privadas de Santa Maria - RS (SOARES, José Galdino Barreto; BELIEIRO JUNIOR, José Carlos Martines)

caracterizam como organizações secundaristas do tipo III. Este estudo também revelou que mesmo contando com a presença de muitos discentes nos eventos realizados pelos grêmios estudantis, como nos jogos interséries, nas festas de natal entre outros, essas organizações não conseguem atrair os outros alunos não membros para participarem dos assuntos relacionados a entidade, como por exemplo, a presença em reuniões e assembleias. Essa ausência dos estudantes não membros nas assembleias e reuniões pode ser uma das razões que faz com que as tomadas de decisões nos grêmios estudantis sejam realizadas, apenas, pelos membros que compõem as direções.

O grêmio estudantil $E$ foi à única entidade estudantil que apresentou características de Organização Secundarista do tipo I, por realizar atividades de cunho ideológico programático, como, por exemplo, atos, manifestos, protestos, ocupações da escola, debates feministas, etc.. Um dos argumentos teóricos de Albuquerque (1977) é que em organizações de tipo partidário, a participação é mais intensa, e mais fraca em organizações de tipo culturais ou de serviços. Entretanto, o grêmio estudantil E, mesmo se caracterizando por ser uma entidade que realiza atividades do tipo I, essa não consegue fazer com que os estudantes, não membros da direção se interessassem pelos assuntos relacionados à entidade. Segundo o presidente do grêmio E "Essas pautas de cunho político parecem que assustaram os outros alunos, prejudicando a mobilização para a participação deles no grêmio estudantil". Enfim, ficou constatado que os sete grêmios estudantis se caracterizam por terem pouca presença dos estudantes nos espaços formais.

O estudo mostra que, na maioria das vezes, os estudantes tendem a participar dos eventos promovidos pelos grêmios estudantis, entretanto essa presença não é revertida em participação em reuniões e assembleias. Desse modo, o estudo permite precisar que todos os grêmios estudantis de Santa Maria nas gestões de 2017 e 2018 não estão conseguindo fazer com que os estudantes não membros da direção participem das reuniões e assembleias, independente do tipo de atividade realizada pelas direções.

Assim, nos limites impostos pela pesquisa, acredita-se que a hipótese que os grêmios estudantis de Santa Maria se caracterizam por serem organizações secundaristas do tipo III tende a se confirmar, assim como no estudo de Albuquerque (1977) que afirma que a intensidade da participação tende ser mais fraca quando 
Artigo | Organização e dinâmica da mobilização e participação política: os grêmios estudantis das escolas públicas e privadas de Santa Maria - RS (SOARES, José Galdino Barreto; BELIEIRO JUNIOR, José Carlos Martines)

integrada a associações culturais e de serviços. Este estudo mostrou que é baixa a participação dos estudantes não membros da direção inclusive no grêmio estudantil que apresentou características de "organização secundarista do tipo político l" ou partidária, contrariando um dos resultados de pesquisa de Albuquerque (1977) que demostra que neste tipo de associação partidária a participação tende ser mais intensa.

Durante o presente estudo algumas questões apareceram e não foram respondidas devido à limitação metodológica adotada neste artigo, abrindo caminhos para estudos futuros relacionados, por exemplo, às razões que fazem com que as estudantes sejam maioria nas direções dos grêmios estudantis e o porquê dos estudantes não membros das direções estarem presentes somente nos eventos promovidos pelos grêmios estudantis e não comparecerem nas reuniões e assembleias da entidade, nos locais onde ocorrem as discussões das pautas e a tomada de decisão; outra possibilidade de pesquisa é sobre a dificuldade da continuidade dos grêmios de Santa Maria.

\section{Referências}

ALBUQUERQUE, J. A. Guilhon. Movimento estudantil e consciência social na América Latina, Rio de Janeiro: Paz e Terra, 1977.

ALMOLD, Gabriel A.; POWELL JR, G. Bingham. Uma Teoria de Política Comparada. Rio de Janeiro: Zahar Editores, 1972.

ALMOND, Gabriel A. \& VERBA, Sidney. La Cultura Civica. Estudio sobre la Participacion Politica Democratica em Cinco Naciones. Madrid: Fundacion Foessa, 1970.

BARNES, S.H.; KAASE, M (org.). Political action: Mass participation in five Western democracies. Beverly Hills: Sage, 1979.

BERELSON,B. R., LAZARSFELD, P. F., \& McPHEE, w: N. Voting: A study of opinion formation in a presidential campaign. Chicago: University of Chicago Press, 1954.

BORBA, J. Participação Política: A Centralidade dos Repertórios. Revista Debates, v. 6, n. 1 , p. 123, 2012b.

BORBA, J. Participação política: uma revisão dos modelos de classificação. Sociedade e Estado, v. 27, n. 2, p. 263-288, 2012.

BORBA, J.; RIBEIRO, E. A. Participação convencional e não convencional na América Latina. Revista Latino-Americana de Opinión Pública, v. 1, p. 53-76, 2010.

BOURDIEU, P. A juventude é apenas uma palavra. Questões de sociologia, p. 112-121. Rio de Janeiro: Marco Zero, 1983.

CAMPBELL, A., CONVERS, P. E., MILLER, W., \&. STOKESt, D. The American voter. New York: Wiley, 1960. 
Artigo | Organização e dinâmica da mobilização e participação política: os grêmios estudantis das escolas públicas e privadas de Santa Maria - RS (SOARES, José Galdino Barreto; BELIEIRO JUNIOR, José Carlos Martines)

CAMPBELL, A., GURIN, G., \& MILLER, W. E. The voter decides. Evanston, III.: Row, Peterson,1954.

COORDENADORIA REGIONAL DE EDUCAÇÃO - 8․ Disponível em: < http://www.educacao.rs.gov.br/estatisticas-da-educacao > acesso em: 18 em set. de 2018.

EISENSTADT, S. N. De geração a geração. São Paulo, Perspectiva, (Coleção Estudos, 41), 1976.

FORACCHI, M. M. O estudante e a transformação da sociedade brasileira. São Paulo: Editora Nacional, 1965.

GOHN, Maria da Glória. Jovens na Política na Atualidade - uma nova cultura de participação. Caderno CR H, Salvador, v. 31, n. 82, p. 117-133, Jan./Abr. 2018.

Teoria dos Movimentos Sociais Paradigmas Clássicos e

Contemporâneos. Edições Loyola, São Paulo, 1997.

JENKINS, J. Craig. Sociopolitical Movements. In: LONG, Samuel L. (Org.). The Handbook Of Political Behavior. Vol. 4. 1981, p. 81-148.

KASSIMIR, Rona, FLANAGAN, Constance. Youth Civic Engagement in the Developing

World: Challenges and Opportunities. In: SHERROD, Lonnie R., TORNEY-PURTA, Judith, FLANAGAN, Constance A. Handbook of Research on Civic Engagement in Youth. 2010, $91-114$.

McADAM, Doug. Political Process and the Development of Black Insurgency. 19301970.University of Chicago Press.1982.

McADAM, Doug, McCARTHY, John D., ZALD, Mayer N. Comparative Perspectives on Social Movements: Political Opportunities, Mobilizing Structures, and Cultural Framings. 1996. MCINTOSCH, Hugh, YOUNISS, James. Toward a Political Theory of Political Socialization of Youth. In: SHERROUD, Lonnie R., TORNEY-PURTA, Judith, Constance A. JOHN WILEY, Flanagan (Org.). Handbook of Research on Civic Engagement in Youth. 2010, p. 23-42.

METZGER, Aaron, SMETANA, Judith G. Social Cognitive Development and Adolescent Civic Engagement. In: SHERROUD, Lonnie R., TORNEY-PURTA, Judith, Constance A. JOHN WILEY, Flanagan (Org.). Handbook of Research on Civic Engagement in Youth. 2010, p. 221-248.

MILBRATH, Lester W. Political participation. Chicago: Rand McNally, 1965.

MILBRATH, Lester W. Political participation. In: LONG, Samuel L. (Org.). The Handbook Of Political Behavior. Vol. 4. 1981, p. 197-237.

NORRIS, Pippa. "Political Activism: New Challenges, New Opportunities", in BOIX, Carles and Susan Stokes (eds.). The Oxford Handbook of Comparative Politics. New York: Oxford University Press, 2007, 628-649.

Pizzorno, Alessandro. “Condizioni della participazione política”. IN: Pizzorno,

Alessandro. Le radici dela politica assoluta. Feltrinelli, Milão, 1966.

PLANALTO. Disponível em: < http://www.planalto.gov.br/ccivil_03/leis/L7398.htm > acesso em: 10 em set. de 2018.

PLANALTO. Disponível em: < http://www.planalto.gov.br/ccivil_03/LEIS/L8069.htm > acesso em: 10 em set. de 2018.

PLANALTO. Disponível em: < http://www.planalto.gov.br/ccivil_03/_Ato20152018/2015/Decreto/D8537.htm > acesso em: 10 em set. de 2018.

RIBEIRO, E.A. Valores pós-materialistas e cultura política no Brasil. Tese (Doutorado em Sociologia), Curitiba, UFPR, 2008. 
Artigo | Organização e dinâmica da mobilização e participação política: os grêmios estudantis das escolas públicas e privadas de Santa Maria - RS (SOARES, José Galdino Barreto; BELIEIRO JUNIOR, José Carlos Martines)

Ribeiro, Ednaldo; Borba, Julian. Participação Política na América Latina. Eduem, Maringá, 2015.

RIBEIRO, E. A.; BORBA, J. Participação e pós-materialismo na América Latina. Opinião Publica, v. 16, n. 1, p. 28-64, 2010.

TARROW, Sidney. Struggling to Reform: Social Movements and Policy Change During Cycles o Protest. Western Societies Program Occasional Paper No. 15. New York Center for International Studies, Cornell University, Ithaca, N.Y. 1983.

TILLY, Charle. From Mobilization to Revolution. Reading, Mass.: Addison-Wesley, 1978.

UNIÃO BRASILEIRA DOS ESTUDANTES SECUNDARISTAS. Disponível em: $<$ http://ubes.org.br/>. Acesso em set. de 2018.

UNIÃO GAÚCHA DOS ESTUDANTES. Disponível em: <https://uges.org.br>. Acesso em: set.de 2018.

UMES. Disponível em: < https://www.umessm.org.br/index.php?p=convenios>. Acesso em: nov. de 2018.

UNIÃO NACIONAL DOS ESTUDANTES. Disponível em: <https://une.org.br/>. Acesso em: set. de 2018.

VAN DETH, J. W. Studying political participation: towards a theory of everything?. In: Trabalho aprensentado em Joint Session of Workshops of the European Consortium for Political Research-Grenoble, Abril. 2001. p. 6-11.

VAN DETH, J. W. Private Groups and Public Life: Social Participation, Voluntary Associations and Political Involvement in Representative Democracies. London and New York: Routledge, 1997, pp.01-24.

VERBA, S., SCHLOZMAN, K.L.; BRADY, H.E. Voice and equality. Civic voluntarism in American politics. Cambridge, Mass.: Harvard University Press, 1995.

The unheavenly chorus: unequal political voice and the broken promise of American democracy. Princeton: Princeton University Press, 2012.

VERBA, S.; NIE, N. Participation in America: Social equality and political democracy. New York: Harper\& Row, 1972.

ZUKIN, Cliff, KEETER, Scott, ANDOLINA, Molly, JENKINS, Krista e CARPINI, Michael X. D. A New Engagement? Political Participation, Civic Life, and the Changing American Citizen. 2006. 